\title{
AN UNUSUAL TUMOUR IN THE UMBILICAL REGION
}

\author{
By Martin A. Goodwin, M.R.C.S., L.R.C.P. \\ (Resident Surgical Officer, Withington Hospital, Manchester).
}

Basal celled tumours arising from the sweat glands of the skin are relatively uncommon, and as far as we are aware a tumour of this type in the region of the umbilicus has not previously been described. That certain basal celled tumours in fact arise from sweat glands is becoming increasingly recognised, and Savatard (I94I), and Warren and Warvi (r943), have recently reviewed the literature and described the histological findings.

Cullen (IgI6), in his book The Umbilicus and Its Diseases, quotes four cases, including one of his own, in which sweat glands have been found associated with adenomyoma of uterine origin, but does not consider that any of these cases are true sweat gland tumours. He further states, "Although as a rule there are no sweat glands in the umbilicus, nevertheless the normal skin is so close to it that a tumour consisting of sweat glands might so encroach upon the umbilicus that it could not be distinguished from one growing in the umbilical region." This statement is borne out by the present case.

\section{Case Report}

The patient, a married woman aged 39 years, stated that she had noticed, for six years, a small reddish lump in the umbilicus, which occasionally discharged yellow material with an unpleasant odour. For six months she had had "prickly feelings" in the umbilicus which were worse during menstruation. There was no history of any other skin lesions on the trunk or extremities, and nothing of importance in the family history.

On examination there was a raised purplish nodule, approximately $\mathrm{r} \cdot 5 \mathrm{~cm}$. in diameter, in the centre of the umbilicus; and at the left side of this there was a small firm red projection (Fig. I). The patient stated that the purple portion had arisen later and that the whole was steadily growing larger. Nothing else abnormal was detected on routine examination of the patient.

\section{Diagnosis}

The following conditions were considered:

I. Endometriosis of the umbilicus. This was considered most probable in view of the fact that the swelling looked as though it contained blood and tended to be more painful during menstruation.

2. An umbilical polyp arising from the mucosa of a Meckel's diverticulum.

3. A pyogenic granulomatous condition.

\section{Operation}

Under general anaesthesia the umbilicus was removed together with an ellipse of surrounding skin. There was no evidence of a fistulous track or other abnormal connection between the base of the umbilicus and the deeper tissues.

\section{Pathological Report}

A diamond shaped piece of skin and subcutaneous tissue approximately $8 \mathrm{~cm}$. in length and $4 \mathrm{~cm}$. in width and a maximum depth of $3 \mathrm{~cm}$. In the centre of it is the umbilicus and immediately above it and to the right is a swelling approximately $\mathrm{I} \cdot 5 \mathrm{~cm}$. in diameter, which passes into the middle of the umbilicus. The surface of the swelling is purplish-blue. The cut surface shows the swelling to be composed in its lower part of solid buff-coloured tissue, while the upper third is a thin walled cyst containing blood and clot (Fig. 2).

\section{Microscopical Examination}

The skin epithelium is slightly thickened in the navel fold. The structure of the tumour varies much in different parts of the section. Most typically it consists of broad sheets of mediumsized and flattened cells with round or oval deeply staining nuclei and a small amount of cytoplasm, but in the centre of these groups are larger cells with clearer cytoplasm and with the general features of sweat gland cells. Throughout there are many small cystic spaces lined with a single layer of cuboidal cells. At one point the tumour cells appear to be continuous with the basal layer of the surface epithelium. The large cyst has a lining of tumour tissue of varying thickness similar to that previously described and continuous with the main tumour mass. The lumen contains blood some of which is in process of absorbtion by the epithelial cells (Fig. 3).

\section{Opinion}

The specimen is a tumour of sweat gland origin. It has some features of basal cell carcinoma, but does not appear to be definitely in the malignant group.

I wish to express my thanks to Mr. H. T. Cox, Visiting Surgeon, for permission to report this case.

\section{REFERENCES}

CULLEN (rgI6), Umbilicus and Its Diseases. Saunders. SAVATARD, L. (I 94I), British J. Derm., 53, 2 I4.

WARREN, S., and WARVI, W. N. (1943), Amer. J. Path., 19, 44 I. 
UNUSUAL TUMOUR IN THE UMBILICAL REGION MARTIN A. GoODwin, M.R.C.S., L.R.C.P.

FIg. I.-Tumour of the umbilicus before removal.

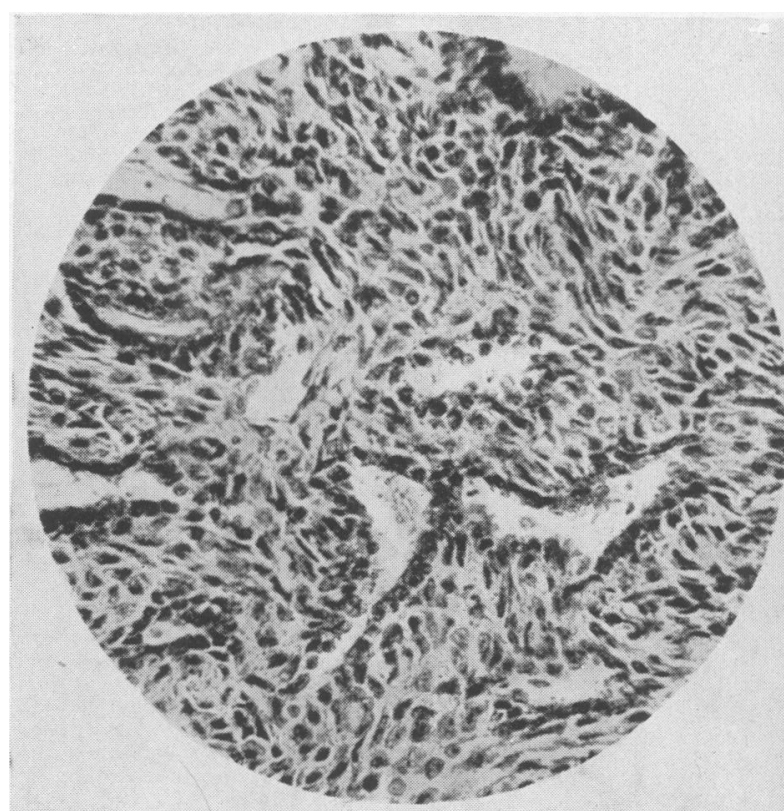

FIG. 3.-Microphotograph of section of sweat gland tumour ( $x$ 450).

Fig. 2.-Photograph of the cut section of the tumour ( $\left.\begin{array}{l}x \\ 5\end{array}\right)$

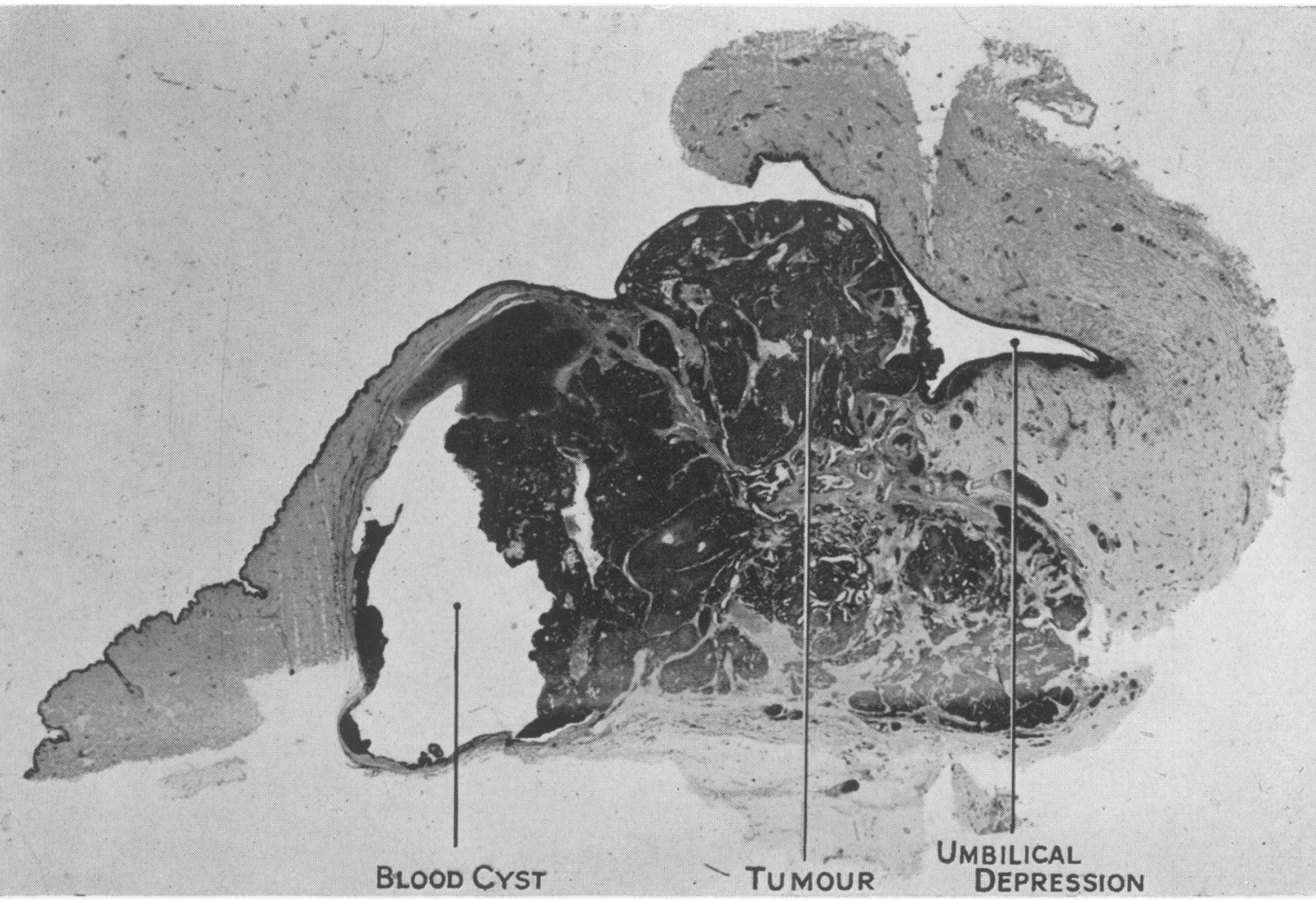




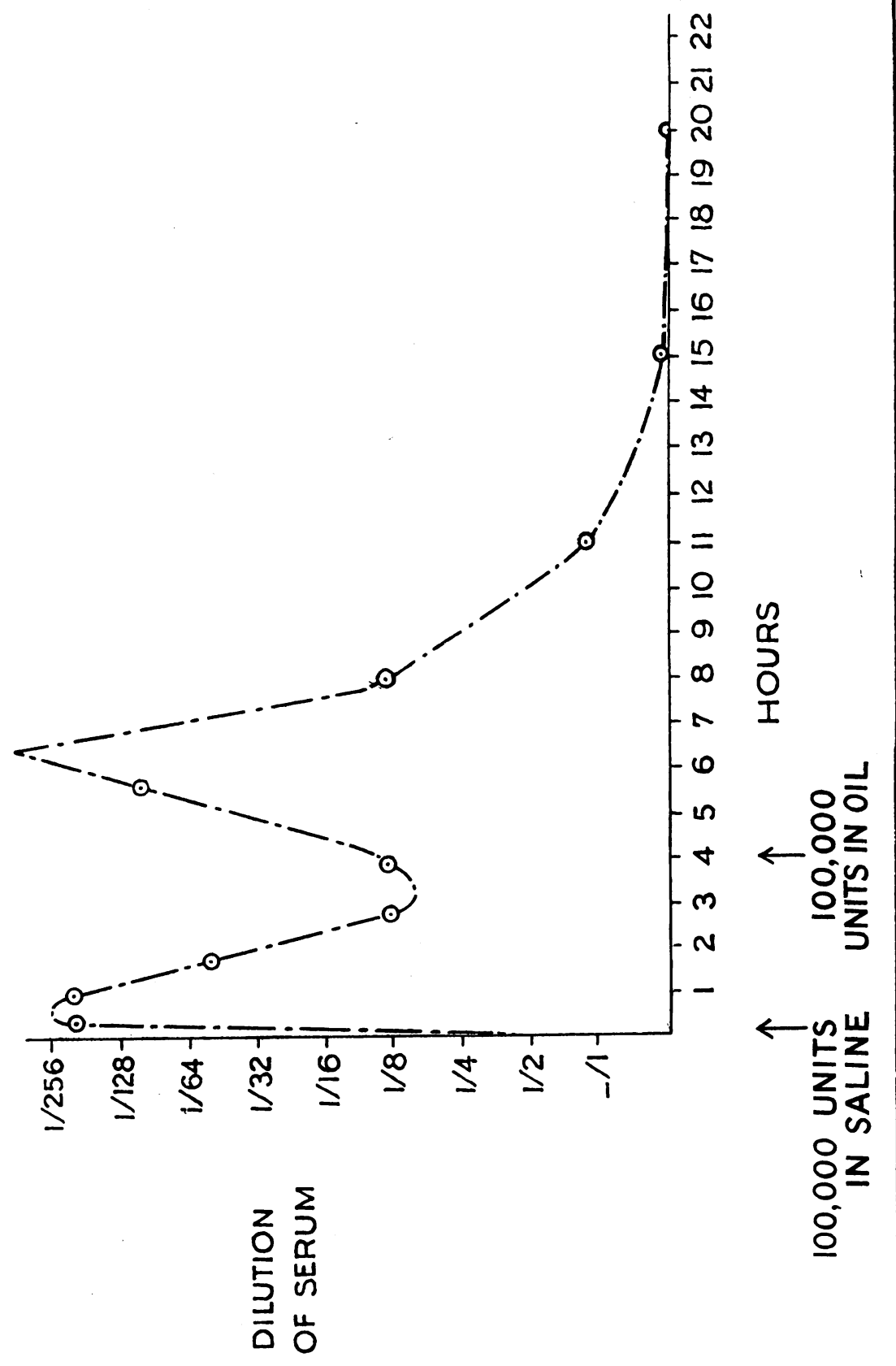

